Int. J. Electrochem. Sci., 12 (2017) 4134 - 4149

\title{
Electrochemical and Quantum Chemical Investigations of some Cyanoacetamide Derivatives as Eco-Friendly Corrosion Inhibitors for Aluminum-Silicon Alloy in Acidic Solution
}

\author{
A. S. Fouda ${ }^{1, *}$, A.M.Eldesoky ${ }^{2}$, F.Sh.Mohamed ${ }^{3}$ and M. W. El-Sherbeni ${ }^{1}$ \\ ${ }^{1}$ Department of Chemistry, Faculty of Science, El-Mansoura University, El-Mansoura-35516, Egypt \\ ${ }^{2}$ Engineering Chemistry Department, High Institute of Engineering \&Technology (New Damietta), \\ Egypt and Al-Qunfudah Center for Scientific Research (QCSR), Chemistry Department, Al- \\ Qunfudah College, Umm Al-Qura University, KSA. \\ ${ }^{3}$ Department of Chemistry, Faculty of Science, Damietta University, Damietta, Egypt. \\ *E-mail: asfouda@hotmail.com
}

doi: $10.20964 / 2017.05 .10$

Received: 27 December 2016/Accepted: 28 February 2017 / Published: 12 April 2017

Cyanoacetamide derivatives $(\mathrm{CyD})$ were investigated as eco-friendly corrosion inhibitors at various doses for alloy $(\mathrm{Al} / \mathrm{Si})$ in one molar $\mathrm{HCl}$ utilized Tafel polarization (TP), (EFM) electrochemical frequency modulation and (EIS) impedance method. The temperature influence on corrosion behaviour with appending of various doses was carried out in range of temperature of $25-45^{\circ} \mathrm{C}$ by EFM technique. TP plots revealed that the investigated $\mathrm{CyD}$ were of mixed-type. The protection efficiency $(\% \eta)$ was found to rise with increasing the concentration of investigated CyD but decrease with improving the medium temperature. CyD adsorption on $\mathrm{Al} / \mathrm{Si}$ alloy surface was found to obey Temkin isotherm. Some adsorption and activation thermodynamic functions were measured and explained. The order of the $\% \eta$ of $\mathrm{CyD}$ is given: $(\mathbf{1})>(\mathbf{2})>(\mathbf{3})$. It was noted that the data of quantum chemical calculations run parallel to the rise in $\% \eta$ given which support the preceding order.

Keywords: Cyanoacetamide derivatives, Al-Si alloy, HCl, TP, EIS, EFM

\section{$\underline{\text { FULL TEXT }}$}

(C) 2017 The Authors. Published by ESG (www.electrochemsci.org). This article is an open access article distributed under the terms and conditions of the Creative Commons Attribution license (http://creativecommons.org/licenses/by/4.0/). 